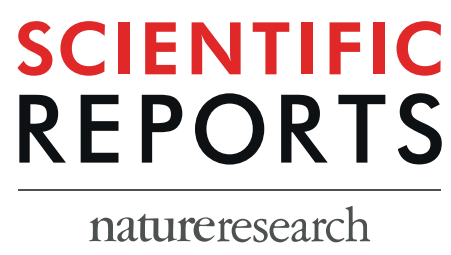

Check for updates

\title{
Antioxidants help favorably regulate the kinetics of lipid peroxidation, polyunsaturated fatty acids degradation and acidic cannabinoids decarboxylation in hempseed oil
}

Anubhav Pratap Singh ${ }^{\bowtie}$, Farahnaz Fathordoobady, Yigong Guo, Anika Singh \& David D. Kitts

The seed of the hemp plant (Cannabis sativa L.) has been revered as a nutritional resource in Old World Cultures. This has been confirmed by contemporary science wherein hempseed oil (HSO) was found to exhibit a desirable ratio of omega- 6 and omega- 3 polyunsaturated fatty acids (PUFAs) considered optimal for human nutrition. HSO also contains gamma-linoleic acid (GLA) and non-psychoactive cannabinoids, which further contribute to its' potential bioactive properties. Herein, we present the kinetics of the thermal stability of these nutraceutical compounds in HSO, in the presence of various antioxidants (e.g. butylated hydroxytoluene, alpha-tocopherol, and ascorbyl palmitate). We focussed on oxidative changes in fatty acid profile and acidic cannabinoid stability when HSO was heated at different temperatures $\left(25^{\circ} \mathrm{C}\right.$ to $\left.85^{\circ} \mathrm{C}\right)$ for upto $24 \mathrm{~h}$. The fatty acid composition was evaluated using both $\mathrm{GC} / \mathrm{MS}$ and ${ }^{1} \mathrm{H}-\mathrm{NMR}$, and the cannabinoids profile of $\mathrm{HSO}$ was obtained using both HPLC-UV and HPLC/MS methods. The predicted half-life (DT50) for omega- 6 and omega-3 PUFAs in HSO at $25^{\circ} \mathrm{C}$ was about 3 and 5 days, respectively; while that at $85^{\circ} \mathrm{C}$ was about 7 and 5 hours respectively, with respective activation energies $\left(E_{a}\right)$ being $54.78 \pm 2.36$ and $45.02 \pm 2.87 \mathrm{~kJ} / \mathrm{mol}$. Analysis of the conjugated diene hydroperoxides $(\mathrm{CDH})$ and $p$-Anisidine value $(p-\mathrm{AV})$ revealed that the addition of antioxidants significantly $(p<0.05)$ limited lipid peroxidation of HSO in samples incubated at $25-85^{\circ} \mathrm{C}$ for $24 \mathrm{~h}$. Antioxidants reduced the degradation constant $(k)$ of PUFAs in HSO by upto $79 \%$. This corresponded to a significant $(p<0.05)$ increase in color stability and pigment retention (chlorophyll $a$, chlorophyll $b$ and carotenoids) of heated HSO. Regarding the decarboxylation kinetics of cannabidiolic acid (CBDA) in $\mathrm{HSO}$, at both $70^{\circ} \mathrm{C}$ and $85^{\circ} \mathrm{C}, \mathrm{CBDA}$ decarboxylation led to predominantly cannabidiol (CBD) production. The half-life of CBDA decarboxylation (originally 4 days) could be increased to about 17 days using tocopherol as an antioxidant. We propose that determining acidic cannabinoids decarboxylation kinetics is a useful marker to measure the shelf-life of HSO. The results from the study will be useful for researchers looking into the thermal treatment of hempseed oil as a functional food product, and those interested in the decarboxylation kinetics of the acidic cannabinoids.

The nutritional value of hemp seed, a by-product of the plant fibre industry, is attributed to both a high-quality protein content $(25 \%)$, containing all essential amino acids, and a high-quality lipid content $(>30 \%)$ which includes all essential fatty acids, and also gamma linoleic acid (GLA) (FAO/WHO). Hempseed oil (HSO) is generally obtained by cold pressing of the seed, which contains a rich source of essential polyunsaturated fatty acids (PUFA). The ratio $(2.1: 1$ to $3: 1)$ of linoleic acid $(18: 2, \omega-6)$ to alpha-linolenic acid $(18: 3, \omega-3)$ in HSO provides a balanced fatty acid substrate for downstream n- 6 and n-3 eicosanoid production ${ }^{1}$, respectively; critical reactions 
known for maintaining cell membrane structure and regulating prostaglandins and leukotrienes synthesis pathways. These bioactive agents are responsible for ensuring a balance between homeostasis and physiological mechanisms that include anti-/pro-aggregation, vasodilation, and anti/pro-inflammatory properties ${ }^{2-4}$. In this regard, Canada has recently paid attention to the production of legal industrial hemp that contains less than $0.3 \%$ of $\Delta$-9-tetrahydrocannabinol ( $\triangle \mathrm{THC}$ ) as well as hemp seed oil (HSO) $)^{5,6}$.

Thermal degradation and oxidation are two reactions that produce undesirable changes in edible oils that carry over through processing and storage, and which can result in changes in safety, sensory, and the nutritive value of the oil. Hence, information regarding oxidative and thermal stability of the HSO is indispensable for maintaining quality control for applications that involve its use as an ingredient in food formulations ${ }^{7}$, or as an ingredient in numerous cosmetic, nutraceutical and functional food products ${ }^{8,9}$. Various methods, including determination of primary oxidation (e.g. peroxide value, conjugated dienes) and secondary oxidation (e.g. $p$-Anisidine value, TBARS, and headspace volatile) are commonly used to monitor the oxidation stability of edible oils and also to predict the shelf-life ${ }^{10}$. As lipid oxidation is a relatively slow process at room temperatures, accelerated storage study performed using higher temperatures (i.e. $60-90^{\circ} \mathrm{C}$ ) is often performed ${ }^{11}$. Arrhenius plots are used to predict oxidative stability and shelf-life of a food product ${ }^{12}$. Also of particular interest are the cannabinoid compounds, with typically higher concentrations of non-psychoactive cannabinoids, including cannabidiolic acid (CBDA) and cannabidiol (CBD), compared to psychoactive compounds tetrahydrocannabinolic acid (THCA), and tetrahydrocannabinol (THC). Although these compounds are present in only small quantities, they have medical interest due to their bioactive anti-convulsive, anti-epileptic, and anti-microbial effects ${ }^{8}$. Acidic cannabinoid acids such as CBDA convert to corresponding neutral forms through a decarboxylation reaction that is catalyzed by heat. Hence, the changes of CBDA/CBD ratio in $\mathrm{HSO}$ can be considered as a useful indicator for monitoring HSO storage life.

Numerous studies ${ }^{13,14}$ have evaluated the potential of using different antioxidants to delay auto-oxidation reactions, in edible oils, particularly when exposed to high temperature processing. However, the specific effect of antioxidants on thermal-induced degradation kinetics of omega- 6 and omega- 3 fatty PUFAs, along with simultaneous changes of cannabinoids has not been reported.

In a previous work ${ }^{15}$, we demonstrated the efficacy of natural plant extracts (rosemary, sage and thyme) in inhibiting the formation of hydroperoxides and preservation of vitamin E levels and omega-3 fatty acid profile during high temperature processing and storage of hempseed and soybean oils. The current study aims to establish the kinetic parameters for modelling of fatty acids degradation and acidic cannabinoids decarboxylation of hempseed oil. We also evaluate the pigment content and correlate it with color changes, study the effect of heat treatment on lipid peroxidation levels, evaluate the fatty acid concentration and identify the cannabinoids present in the HSO. Further, we assess how these kinetic parameters are regulated in the presence of 3 different antioxidants (butylated hydroxytoluene, alpha-tocopherol, and ascorbyl palmitate) in an attempt to reduce the degradation of both PUFAs ( $\omega-6$ and $\omega-3$ fatty acids) and acidic cannabinoids in HSO.

\section{Materials and methods}

Materials. Unrefined cold-press hempseed oil (HSO) was purchased from Manitoba Harvest Hemp Foods (Winnipeg, Manitoba, Canada). All solvents and chemicals used were analytical and/or HPLC grade.

Oxidative stability and quality of thermally-induced hempseed oil. HSO samples were prepared by adding three individual antioxidants including BHT (positive control) in USDA legislated level of $0.01 \% \mathrm{w} / \mathrm{w}$, alpha-tocopherol $(\alpha-T)$, and ascorbyl palmitate $(\mathrm{AP})$ at concentrations of $0.02 \% \mathrm{w} / \mathrm{w}$ and $0.02 \% \mathrm{w} / \mathrm{w}$ respectively. Considering the molecular weight of $\alpha-\mathrm{T}(430.72 \mathrm{~g} / \mathrm{mol})$ and AP $(414.53 \mathrm{~g} / \mathrm{mol})$, which is about twofold that of BHT $(220.4 \mathrm{~g} / \mathrm{mol})$, when added in the similar weight to BHT, they provide approximately half reactive moles. Hence, to provide the same molar ratio, the amount of $0.02 \% \mathrm{w} / \mathrm{w}$ were chosen for both natural antioxidants ( $\alpha$-T and AP). The samples incubated at $40,55,70$ and $85^{\circ} \mathrm{C}$ for $24 \mathrm{~h}$ together with original HSO (negative control). The samples were retrieved at regular time intervals for determination of pigment content (Chlorophyll $a$, Chlorophyll $b$ and carotenoids), and color properties $\left(\Delta E^{*}\right)$ along with conjugated diene hydroperoxides (CDH), $p$-Anisidine value $(p-\mathrm{AV})$, fatty acids profile and cannabinoids analysis (CBDA). All experiments were performed in triplicate. Results were compared with samples stored at $25^{\circ} \mathrm{C}$ for 15 days $(360 \mathrm{~h})$.

Chlorophyll $a$, Chlorophyll $b$ and carotenoids contents. Chlorophyll $a$ and $b$, and total carotene were determined according to Aladic et al. ${ }^{16}$. HSO samples were dissolved in diethyle ether (pure solvent) in the ratio of $1 / 50$ (w/v) in an ultrasonic bath following by homogenizing for 30 seconds and centrifuging at $3000 \mathrm{rpm}$ for 10 minutes. Using an UV-Vis spectrophotometer (Varian Cary, 50 MPR Microplate Reader, USA), absorbance of the supernatant was measured at 400-700 nm. Chlorophyll $a$ represented the maximum absorbance at $660 \mathrm{~nm}$, chlorophyll $b$ at $642.5 \mathrm{~nm}$, and the total carotene at $470 \mathrm{~nm}$. All tests were performed triplicate. The concentration of pigments $(\mu \mathrm{g} / \mathrm{g})$ was calculated on the basis of Lambert-Beer Law using Eqs. (1-3).

$$
\begin{gathered}
\text { Chlorophyll } a=10.5 \mathrm{~A}_{660}-0.97 \mathrm{~A}_{642.5} \\
\text { Chlorophyll } b=16.36 \mathrm{~A}_{642.5}-2.43 \mathrm{~A}_{660} \\
\text { Total carotene }=\left(1000 \mathrm{~A}_{470}-0.52 \mathrm{Chl}_{a}-36.75 \mathrm{Chl}_{b}\right) / 205
\end{gathered}
$$

The amount of each pigment in the HSO ( $\mu \mathrm{g} / \mathrm{g})$ was calculated using Eq. (4): 


$$
\mathrm{C}=\mathrm{C} 1 \cdot \mathrm{V} \cdot \mathrm{D} / \mathrm{G}
$$

where: $\mathrm{C}=$ amount of pigment in $\mathrm{HSO}((\mu \mathrm{g} / \mathrm{g}) ; \mathrm{C} 1=$ concentration of pigment $(\mathrm{mg} / \mathrm{L}) ; \mathrm{V}=$ initial volume $(\mathrm{mL})$; $\mathrm{D}=$ dilution (if any); $\mathrm{G}=$ oil mass (g).

Color changes $\left(\Delta E^{*}\right)$. The color properties of HSO samples were assessed by by LabScan XE spectrophotometer (HunterLab, VA, USA) equipped with EasyMatch QC software based on the International Commission on Illumination (CIE L* $\left.a^{*} b^{*}\right)$ method. Lightness $\left(L^{*}\right)$, redness $\left(a^{*}\right)$ and yellowness $\left(b^{*}\right)$ attributes were directly measured by system. Then, the total color change of the samples $\left(\Delta E^{*}\right)$ was defined by the total distance between two points in three-dimension CIE $L * a * b *$ of color space.

Conjugated diene hydroperoxides $(\mathrm{CDH})$ test. Conjugated diene hydroperoxides $(\mathrm{CDH})$ associated with primary products of oxidation were measured according to AOCS standard method 2.501 (AOCS 1998). An aliquot of hemp seed oil sample was dissolved in $5 \mathrm{~mL}$ cyclo-hexane and the absorbance of solution was measured at 234 $\mathrm{nm}$ using spectrophotometer (Varian Cary, 50 MPR Microplate Reader, USA). Results (g hydroperoxides per 100 g oil) were reported based on the linoleic acid molar absorptivity as Eq. (5):

$$
C D H(g / 100 g \text { oil })=1.0769 \times A / C(g \text { oil } / 100 \mathrm{ml} \text { solution })
$$

where: $\mathrm{CDH}=$ the value of Conjugated diene hydroperoxides; $\mathrm{A}=$ the absorbance of the sample at $234 \mathrm{~nm}$; $\mathrm{C}=$ concentration

$p$-Anisidine Value $(p-A V)$. The $p$-Anisidine value $(p-A V)$ for determination of secondary oxidation products was measured according to AOCS Official Method Cd 18-90 (2017). HSO samples (2.0 g) were dissolved in 25 $\mathrm{ml} n$-hexane and the absorbance of this solution was measured at $350 \mathrm{~nm}$ against $n$-hexane using spectrophotometer (Varian Cary, 50 MPR Microplate Reader, USA). Then, one $\mathrm{ml}$ of $0.25 \% p$-Anisidine in acetic acid (w/v) was added to $5 \mathrm{ml}$ of the solution and kept in the dark for $10 \mathrm{~min}$. The absorbance of the sample solution was measured at $350 \mathrm{~nm}$ against the control test containing $1 \mathrm{ml}$ of $p$-Anisidine solution and $5 \mathrm{ml} n$-hexane. All tests were performed in triplicate.

The $p$-AV was calculated according to Eq. $(6)^{15}$ :

$$
p-A V=25\left(1.2 A b s_{1}-A b s_{2}\right) / m
$$

where: $p-\mathrm{AV}=$ the value of $p$-Anisidine; $\mathrm{Abs}_{1}=$ the absorbance of the sample solution after 10 min reaction in the dark; $\mathrm{Abs}_{0}=$ the initial absorbance of the sample solution; $m=$ the amount of HSO (g) used in the analysis.

Analysis of fatty acids profile. Sample Preparation: The fatty acid profile was determined by producing methyl esters with potassium hydroxide $2 \mathrm{M}$ in methanol and using gas chromatography (GC-FID) system ${ }^{17}$. An amount of $3 \mathrm{ml}$ heptane was added to $0.10 \pm 0.0 \mathrm{~g}$ HSO in a $15 \mathrm{ml}$ test tube and shaken using vortex for $20 \mathrm{~s}$. Then, the sample was saponified with adding $500 \mu \mathrm{L}$ of methanolic potassium hydroxide $(\mathrm{KOH})$ solution $(2 \mathrm{M})$ and vortexed for another $20 \mathrm{~s}$. HCL ( $2 \mathrm{~N}$ ) was used for eliminating the excessive amount of KOH. The sample was left until the upper layer became clarified. The supernatant comprising of fatty acid methyl esters (FAMEs) was decanted and passed through $0.45 \mu \mathrm{m}$ filters before injection.

Gas-FID Chromatography (GC) condition: (FAMEs) were analyzed by a GC-17A Shimadzu (Shimadzu, Scientific Instruments, Inc., Columbia MD) equipped with a flame ionization detector (FID), Omegawax ${ }^{\mathrm{TM}} 320$ $(30 \mathrm{~m} \times 0.32 \mathrm{~mm}$ ID $\times 0.25 \mu \mathrm{m}$ film thickness) fused silica capillary column and Shimadzu Class-VP Software. The initial column temperature was set at $165^{\circ} \mathrm{C}$ for $10 \mathrm{~min}$ followed by increasing to the final temperature of $200^{\circ} \mathrm{C}$ with a rate of $1.5^{\circ} \mathrm{C} / \mathrm{min}$. The injector and detector temperature were 210 , and $250^{\circ} \mathrm{C}$, respectively. The FAMEs were detected based on the comparison of their retention time to that of the matched peaks of a mixture of fatty acid methyl ester (FAMEs) standard.

GC/MS condition: A Perkin Elmer system of GC-MS (model: Clarus 680-GC - SQ8T Mass Spec.) equipped with TurboMass Ver. 2.3 (NIST 2011) software was used for detection of HSO fatty acids with some changes. Helium (99.99\%) at a constant flow rate of $1 \mathrm{ml} / \mathrm{min}$ was used as carrier gas. Initial temperature was set at $150^{\circ} \mathrm{C}$ holding for $2 \mathrm{~min}$ following by increasing to $185^{\circ} \mathrm{C}$ with $1.5^{\circ} \mathrm{C} / \mathrm{min}$ and reached to $220^{\circ} \mathrm{C}$ with a rate of $5.0^{\circ} \mathrm{C} /$ min A volume of $1 \mu \mathrm{l}$ prepared sample was injected at $250^{\circ} \mathrm{C}$ in a split mode (50:1). MS conditions included ionization energy: $70 \mathrm{eV}$, ion source temperature: $250^{\circ} \mathrm{C}$, and the mass-to-charge $(\mathrm{m} / z)$ range: $20-450$ atomic mass units. Identification of the FAMEs was performed by comparison of their mass spectra and retention times with corresponding data from FAMEs standard.

$H^{1}$ NMR analysis. For NMR studies, the sample was prepared by dissolving $200 \mu \mathrm{L}$ of hemp seed oil in 800 $\mu \mathrm{L}$ of $\mathrm{CDCl}_{3} .{ }^{1} \mathrm{H}$ spectra for $\mathrm{CDCl}_{3}$ solutions were recorded at $600 \mathrm{MHz}$, on a BRUKER AVANCE 600 (with CRYOPROBE). All the data was analyzed by MestReNova.

HPLC-UV and LC-MS analysis. In order to identify the cannabinoids existing in hempseed oil samples, LC-MS analyses were carried out according to Citti et al. ${ }^{18}$ using an Agilent 1290 Infinity/6530 Accurate Mass Q-TOF equipped with MassHunter Workstation software B.07.00. The column was Agilent Zorbax Eclipse Plus C18, $2.1 \times 50 \mathrm{~mm}$, with $1.8 \mu \mathrm{m}$ pore size. Mass spectrometer was operated in dual ionization mode (ESI+ and ESI-). The dry gas at a flow rate of $12 \mathrm{ml} / \mathrm{min}$ and the nebulizer $\left(\mathrm{N}_{2}\right)$ with pressure of $60 \mathrm{psi}$ at $400^{\circ} \mathrm{C}$ and skimmer voltage of $65 \mathrm{~V}$ were used. The capillary voltage was set at $4.0 \mathrm{kV}$. The injection volume was $2.00 \mu \mathrm{L}$ and the mass 

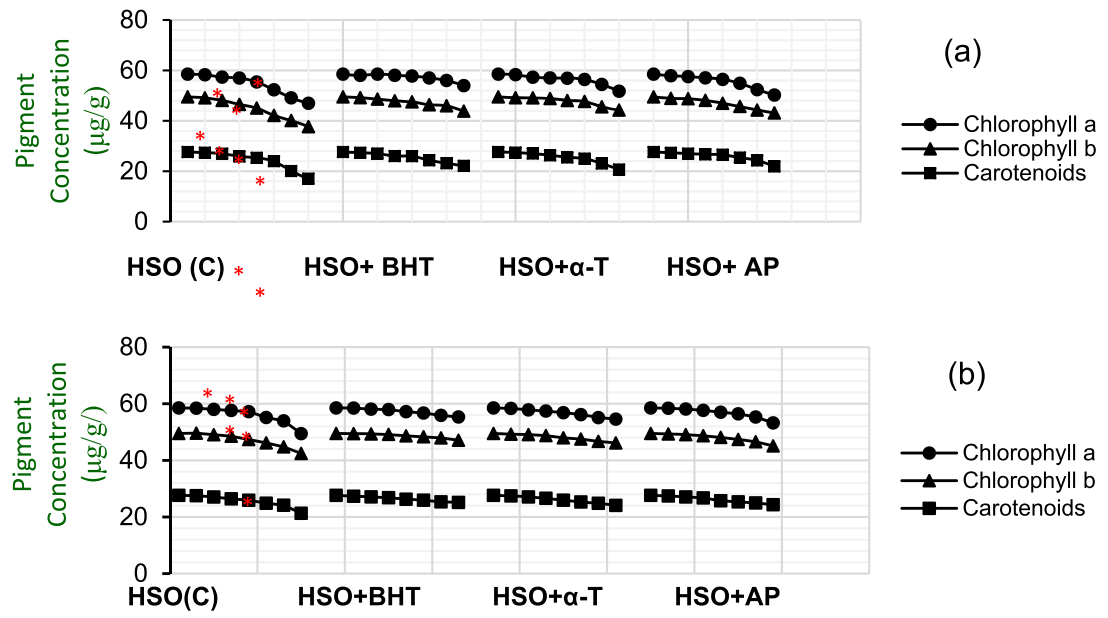

Figure 1. Changes in pigment contents (Chlorophyll a, Chlorophyll $b$ and Carotenoids) of HSO samples during $24 \mathrm{~h}$ heat treatment: $85^{\circ} \mathrm{C}(\mathbf{a}) 70^{\circ} \mathrm{C}(\mathbf{b})$. *Significant difference to samples with antioxidant $(\mathrm{p}<0.05)$.

spectrometer was performed in the range of 50-1000 $\mathrm{m} / \mathrm{z}$. Employing the $\mathrm{m} / z$ corresponding to the molecular ions $[\mathrm{M}+\mathrm{H}]^{+}$, extracted ion chromatograms (EICs) were acquired.

After identifying the cannabinoids composition of hempseed oil samples by LC-MS system, HPLC analyses of cannabinoids were conducted on an Agilent Technologies system series 1100 (Agilent, USA) composed of a quaternary pump, an autosampler, a column heater, and a diod array detector (DAD). Cannabinoids were separated by C18 column (Zorbax, $3.5 \mu \mathrm{m}, 4.6 \mathrm{~mm} \times 150 \mathrm{~mm}$, Agilent, USA) and acquired at $288 \mathrm{~nm}$. The mobile phase was composed of A) water and B) acetonitrile both with $0.1 \%$ formic acid as the buffer in a gradient of $10-100 \% \mathrm{~B}$ for the first $10 \mathrm{~min}$ followed by isocratic elution with $100 \% \mathrm{~B}$ for $5 \mathrm{~min}$ and re-equilibration at $20 \mathrm{~min}$ to the first condition. The mobile phase was pumped at a flow rate of $1.0 \mathrm{ml} / \mathrm{min}$. The column temperature was set at $20^{\circ} \mathrm{C}$. Three injection in volume of $5 \mu \mathrm{L}$ were performed for each sample.

Kinetic studies. Degradation of fatty acids. The degradation kinetics of essential fatty acids ( $\omega$-3 linoleic acid and $\omega-6 \alpha$-linolenic acid) were assessed by incubating HSO samples with/without antioxidants at different levels of temperature $\left(40\right.$ to $\left.85^{\circ} \mathrm{C}\right)$ for $24 \mathrm{~h}$. The same procedure was used for samples stored at $25^{\circ} \mathrm{C}$ for two weeks. The degradation of $\omega-6$ and $\omega-3$ fatty acids followed single first-order kinetic as Eq. (7):

$$
C_{t}=C_{0} \exp ^{-k t}
$$

Where, $\mathrm{C}_{\mathrm{t}}=$ concentration at time $t, C_{0}=$ initial concentration, $e=$ base $\mathrm{e}, k=$ rate constant of degradation $(1 / \mathrm{h})$, $t=$ time.

The rate constant $(k)$ was calculated based on the slope of the $L n$ of fatty acids $(\omega-6, \omega-3)$ retention $(\%)$ vs. time (h) plot. Then, the time needed for 50\% and 90\% degradation (DT50 or half time and DT90) were determined by Eqs. (8) and (9):

$$
\begin{aligned}
& \text { DT50 }=\frac{\operatorname{Ln} 2}{k} \\
& D T 90=\frac{\operatorname{Ln} 10}{k}
\end{aligned}
$$

By using Arrhenius plot between the logarithmic values of $k(L n k)$ versus $1 / T\left(K^{-1}\right)$, the value of the slope corresponds to $-E a / R$ where $E_{a}$ is the activation energy and $R$ is the universal gas constant equal to 8.31441 $\mathrm{J}^{*} \mathrm{~mol}^{-1 *} \mathrm{~K}^{-1}$.

Decarboxylation of CBDA. The decarboxylation kinetics of CBDA and its conversion to CBD were studied by heating HSO samples containing antioxidants as well as control sample at 70 and $85^{\circ} \mathrm{C}$ for $24 \mathrm{~h}$. The decarboxylation of CBDA which followed single first-order kinetics was assessed using Eq. (7). The DT50 and DT90 of the samples were also evaluated using Eqs. (8) and (9).

Statistical analysis. The experimental data are specified as mean \pm SD of three tests. Data were analyzed statistically using Minitab software ver. 18.0 (Pennsylvania, USA). A one-way analysis of variance (ANOVA) followed by Tukey's test was applied for statistical analysis of data at $p<0.05$. 

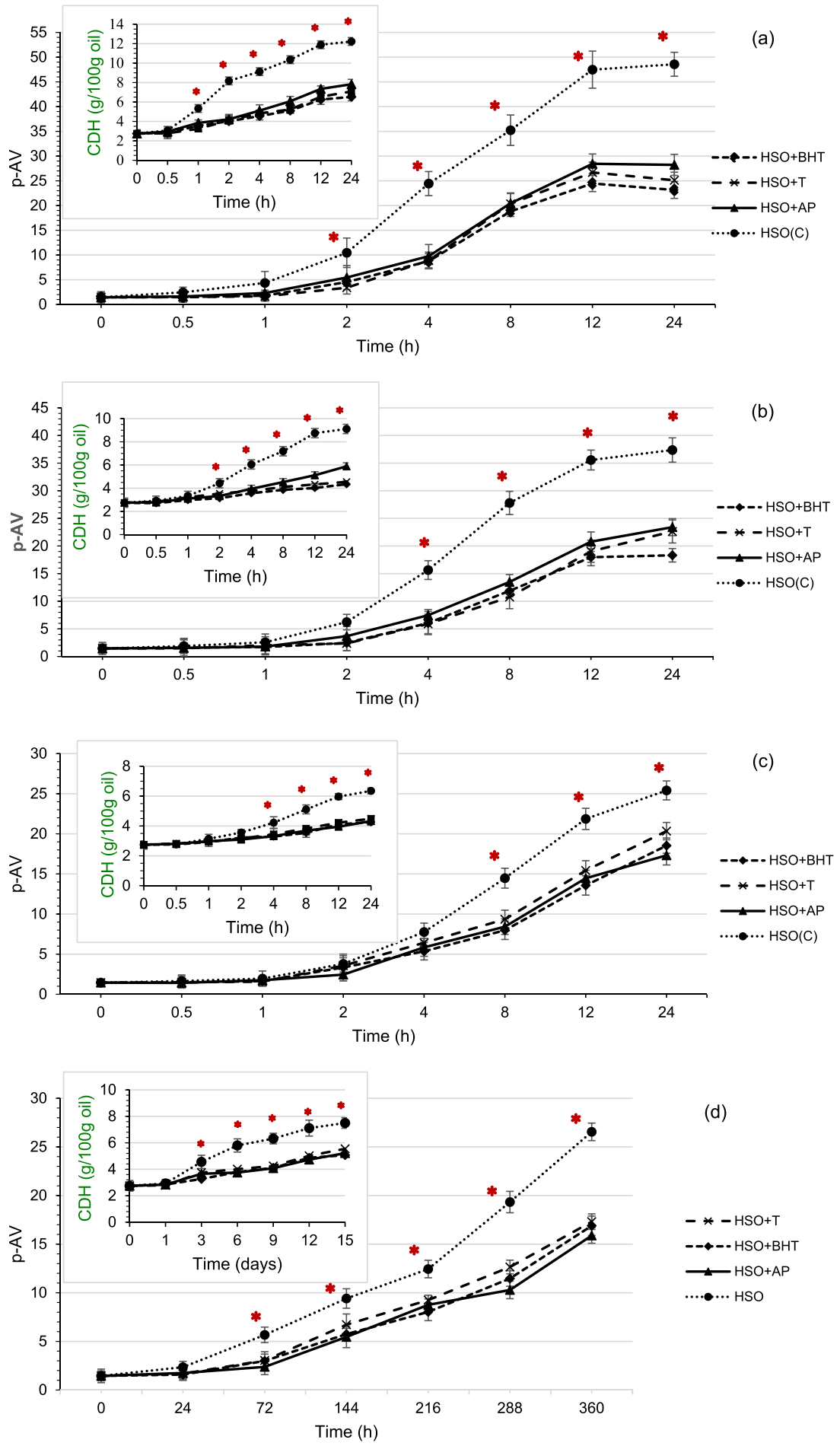

Figure 2. Oxidative status (p-AV and $\mathrm{CDH}$ ) of hempseed oil samples incubated at different temperatures: $85^{\circ} \mathrm{C}$ $(\mathbf{a}), 70^{\circ} \mathrm{C}(\mathbf{b}), 55^{\circ} \mathrm{C}(\mathbf{c})$, and $25^{\circ} \mathrm{C}(\mathbf{d}) *$ Significant difference to antioxidant containing samples $(p<0.05)$.

\section{Results and discussion}

Color changes $\left(\Delta E^{*}\right)$ of thermally-induced hemp seed oil with and without antioxidants and its relation to pigment content. The total color change, expressed as $\Delta E^{*}$ of HSO samples during heating at temperatures between 40 to $85^{\circ} \mathrm{C}$ and at different intervals during $24 \mathrm{~h}$ period is presented in Supplemental Table 1. Results of the control samples, incubated at $25^{\circ} \mathrm{C}$, in dark glass bottles, for 15 days are presented in Supplemental Fig. 1.

Color stability of the HSO improved when antioxidants were added (see Supplemental Table 1). Obón et al. ${ }^{19}$ had shown that color differences that ranged from 0 to 1.5 do not denote significant visual changes; however, when ranges are greater than 5 , significant differences can be distinguished. Using this parameter, we observed a 


\begin{tabular}{|c|c|c|c|}
\hline Fatty acid & $* \mathbf{m} / \mathbf{z}[\mathbf{M}+\mathbf{H}]^{+}$ & $\begin{array}{l}\text { Retention } \\
\text { time (min) }\end{array}$ & $\begin{array}{l}* * \text { Mean } \pm \text { SD } \\
(\%)\end{array}$ \\
\hline $\begin{array}{l}\text { Palmitic acid } \\
(\mathrm{C} 16: 0)\end{array}$ & 256.4 & 4.53 & $6.06 \pm 0.09$ \\
\hline $\begin{array}{l}\text { Stearic acid } \\
(\mathrm{C} 18: 0)\end{array}$ & 248.48 & 6.25 & $2.41 \pm 0.03$ \\
\hline $\begin{array}{l}\text { Oleic acid } \\
\left(\mathrm{C} 18: 1, \omega_{9}\right)\end{array}$ & 282.47 & 6.65 & $6.63 \pm 0.11$ \\
\hline $\begin{array}{l}\text { Linoleic acid } \\
\left(\mathrm{C} 18: 2, \omega_{6}\right)\end{array}$ & 280.44 & 7.50 & $60.52 \pm 0.63$ \\
\hline $\begin{array}{l}\gamma \text {-linolenic } \\
\text { acid }\left(\mathrm{C} 18: 3, \omega_{6}\right)\end{array}$ & 278.43 & 7.87 & $4.33 \pm 0.08$ \\
\hline $\begin{array}{l}\text { Alpha-linolenic } \\
\text { acid }\left(C 18: 3, \omega_{3}\right)\end{array}$ & 278.43 & 8.46 & $18.44 \pm 0.12$ \\
\hline $\begin{array}{l}\text { Stearodonic } \\
\text { acid }\left(\mathrm{C} 18: 4, \omega_{3}\right)\end{array}$ & 276.4 & 8.98 & $0.93 \pm 0.01$ \\
\hline $\begin{array}{l}\text { Eicosenoic acid } \\
\left(\mathrm{C} 20: 1, \omega_{9}\right)\end{array}$ & 310.51 & 9.23 & $0.38 \pm 0.02$ \\
\hline $\begin{array}{l}\text { Decosanoic } \\
\text { acid (C22:0) }\end{array}$ & 340.58 & 9.85 & $0.30 \pm 0.01$ \\
\hline \multicolumn{3}{|l|}{ PUFA } & 84.11 \\
\hline \multicolumn{3}{|c|}{ MUFA } & 7.01 \\
\hline \multicolumn{3}{|c|}{ Saturated fatty acids/Unsaturated fatty acids } & 0.09 \\
\hline \multicolumn{3}{|l|}{$\omega_{6} / \omega_{3}$} & $3.3 / 1$ \\
\hline
\end{tabular}

Table 1. Fatty acid composition of hempseed oil (Cannabis sativa L.) detected and analyzed by GC-MS and GC-FID. *GC-MS results are based on employing the $\mathrm{m} / z$ corresponding to the molecular ions $[\mathrm{M}+\mathrm{H}]^{+}$ **Fatty acid values are the means \pm SD $(n=3)$ of GC-FID peak area percentage $(\%)$.

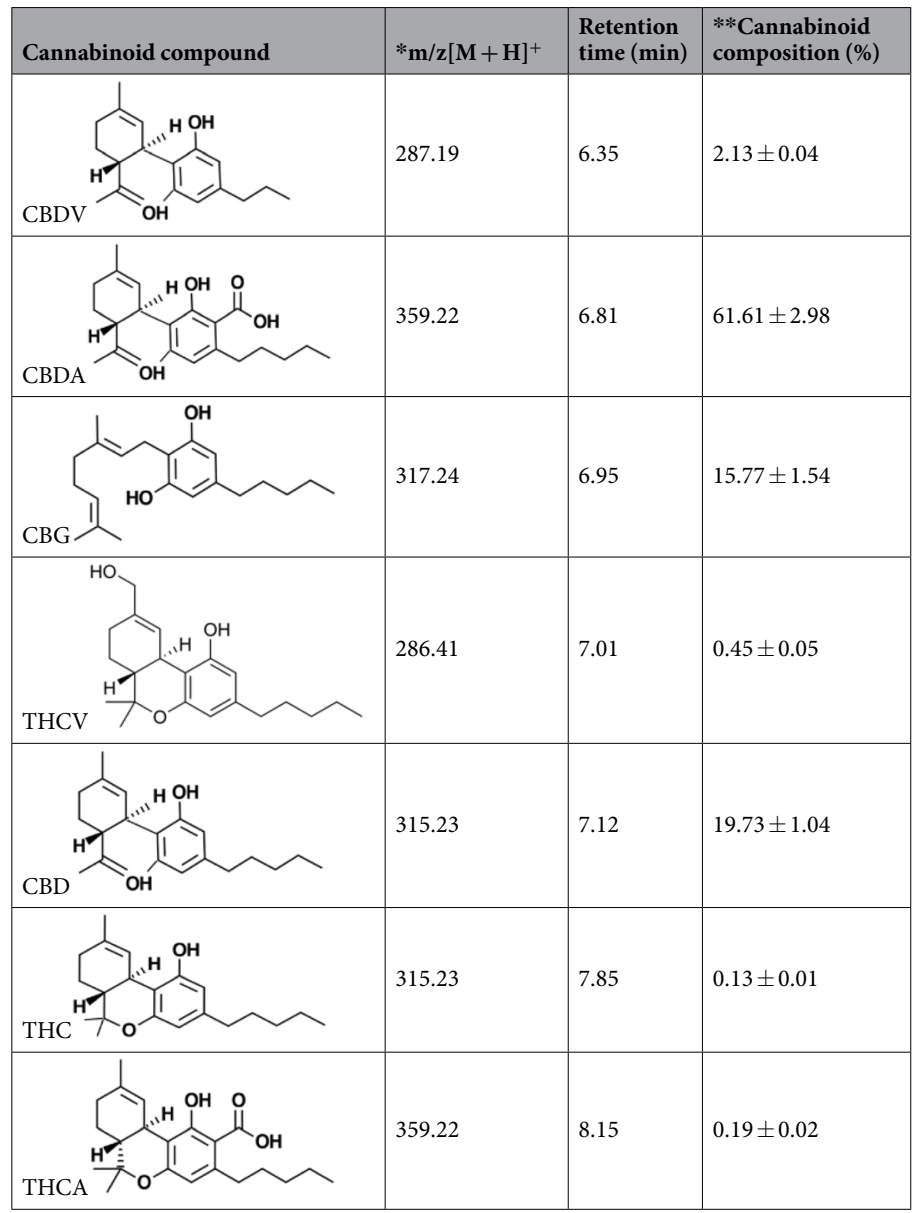

Table 2. Retention times, peak area (\%) (HPLC-UV) and MS spectrometric data (LC-MS) of cannabinoids detected in hempseed oil. *LC-MS results are based on employing the $\mathrm{m} / z$ corresponding to the molecular ions $[\mathrm{M}+\mathrm{H}]^{+* *}$ Cannabinoid composition values are the means of peak area percentage (\%) of HPLC chromatograms $\pm S D(n=3)$. 


\begin{tabular}{|c|c|c|c|c|c|c|c|c|c|}
\hline \multirow{2}{*}{$\begin{array}{l}\text { Incubation } \\
\text { temperature } \\
\left({ }^{\circ} \mathrm{C}\right)\end{array}$} & \multirow[b]{2}{*}{ Sample } & \multicolumn{2}{|l|}{$\mathbf{K}\left(\mathbf{h}^{-1}\right)$} & \multicolumn{2}{|c|}{ DT50 (h) } & \multicolumn{2}{|c|}{ DT90 (h) } & \multicolumn{2}{|l|}{$R^{2}$} \\
\hline & & \multicolumn{2}{|l|}{$\omega-6 \omega-3$} & \multicolumn{2}{|c|}{$\omega-6 \omega-3$} & \multicolumn{2}{|l|}{$\omega-6 \omega-3$} & \multicolumn{2}{|l|}{$\omega-6 \omega-3$} \\
\hline \multirow{4}{*}{25} & HSO & 0.0093 & 0.0055 & 74.21 & 125.45 & 256.51 & 418.18 & 0.94 & 0.87 \\
\hline & $H S O+B H T$ & 0.0035 & 0.0029 & 197.54 & 237.93 & 656.24 & 793.1 & 0.93 & 0.94 \\
\hline & $\mathrm{HSO}+\mathrm{T}$ & 0.0041 & 0.0039 & 166.23 & 176.92 & 552.22 & 589.74 & 0.96 & 0.95 \\
\hline & $H S O+A P$ & 0.0038 & 0.0031 & 182.17 & 222.58 & 605.17 & 741.93 & 0.93 & 0.93 \\
\hline \multirow{4}{*}{40} & HSO & 0.0157 & 0.0148 & 44.13 & 46.62 & 146.60 & 155.40 & 0.92 & 0.93 \\
\hline & $H S O+B H T$ & 0.0081 & 0.0097 & 79.21 & 71.13 & 263.13 & 237.11 & 0.94 & 0.96 \\
\hline & $\mathrm{HSO}+\mathrm{T}$ & 0.0092 & 0.0135 & 70.37 & 51.11 & 233.77 & 170.37 & 0.93 & 0.92 \\
\hline & $H S O+A P$ & 0.0096 & 0.0121 & 72.09 & 57.02 & 239.49 & 190.08 & 0.94 & 0.91 \\
\hline \multirow{4}{*}{55} & HSO & 0.0210 & 0.0309 & 32.86 & 22.33 & 109.15 & 74.43 & 0.94 & 0.96 \\
\hline & $H S O+B H T$ & 0.0113 & 0.0105 & 60.98 & 65.71 & 202.56 & 219.04 & 0.93 & 0.92 \\
\hline & $\mathrm{HSO}+\mathrm{T}$ & 0.0139 & 0.0143 & 49.52 & 48.25 & 164.50 & 160.83 & 0.95 & 0.98 \\
\hline & $H S O+A P$ & 0.0127 & 0.0116 & 54.53 & 59.48 & 181.14 & 198.27 & 0.95 & 0.92 \\
\hline \multirow{4}{*}{70} & HSO & 0.0728 & 0.0487 & 9.47 & 14.16 & 31.59 & 47.22 & 0.98 & 0.90 \\
\hline & $H S O+B H T$ & 0.0184 & 0.0180 & 37.15 & 38.33 & 123.41 & 127.77 & 0.95 & 0.93 \\
\hline & $\mathrm{HSO}+\mathrm{T}$ & 0.0256 & 0.0216 & 26.15 & 31.94 & 86.87 & 106.48 & 0.95 & 0.90 \\
\hline & $H S O+A P$ & 0.0283 & 0.0263 & 24.47 & 26.23 & 81.29 & 87.45 & 0.96 & 0.92 \\
\hline \multirow{4}{*}{85} & HSO & 0.1013 & 0.1367 & 6.81 & 5.04 & 22.70 & 16.82 & 0.96 & 0.98 \\
\hline & $H S O+B H T$ & 0.0293 & 0.0288 & 23.10 & 23.95 & 76.75 & 79.86 & 0.94 & 0.98 \\
\hline & $\mathrm{HSO}+\mathrm{T}$ & 0.0356 & 0.0444 & 19.80 & 15.54 & 65.78 & 51.80 & 0.98 & 0.96 \\
\hline & $H S O+A P$ & 0.0478 & 0.0453 & 14.43 & 15.23 & 48.11 & 50.77 & 0.96 & 0.98 \\
\hline \multicolumn{10}{|l|}{$\mathrm{E}_{\mathrm{a}}(\mathrm{kJ} / \mathrm{mol})$} \\
\hline \multicolumn{2}{|l|}{ HSO } & \multicolumn{3}{|l|}{ HSO + BHT } & \multicolumn{3}{|l|}{ HSO + T } & \multicolumn{2}{|l|}{ HSO + AP } \\
\hline$\omega-6$ & $\omega-3$ & $\omega-6$ & \multicolumn{2}{|l|}{$\omega-3$} & \multicolumn{2}{|l|}{$\omega-6$} & $\omega-3$ & $\omega-6$ & $\omega-3$ \\
\hline $54.78 \pm 2.36$ & $45.02 \pm 2.87$ & $27.35 \pm 1.18$ & \multicolumn{2}{|c|}{$31.17 \pm 2.45$} & \multicolumn{2}{|c|}{$30.41 \pm 2.09$} & $32.28 \pm 1.97$ & $35.97 \pm 2.56$ & $36.66 \pm 2.43$ \\
\hline
\end{tabular}

Table 3. Degradation rate constant ( $k$ ), half-life (DT50), degradation time for $90 \%$ loss (DT90) and activation energy $\left(E_{a}\right)$ of total omega- 6 and total omega- 3 fatty acids of $\mathrm{HSO}$ incubated at $25-85^{\circ} \mathrm{C}$ for $24 \mathrm{~h}$. Data for $\mathrm{K}\left(\mathrm{h}^{-1}\right)$, DT (50), and $\mathrm{R}^{2}$ are the average of three replications Data for $\mathrm{E}_{\mathrm{a}}(\mathrm{kJ} / \mathrm{mol})$ values are the means $\pm \mathrm{SD}$ $(\mathrm{n}=3)$.

marked change in $\Delta E^{*}(6.41)$ and a yellowish tint in heated HSO samples, relative to controls, when incubated at $85^{\circ} \mathrm{C}$, starting at $8 \mathrm{~h}$ and continuing to $24 \mathrm{~h}$. These thermally induced color changes in HSO are likely due to generation of aldehydes, that have known maximum absorption at $350 \mathrm{~nm}$. The color changes of HSO that contained BHT, $\alpha$-T or AP did not exceed the distinguishing value $(>5)$ when incubated at $40^{\circ} \mathrm{C}$ and $55^{\circ} \mathrm{C}$, respectively. HSO that was stored at $25^{\circ} \mathrm{C}$ for 15 days expressed changes in $\Delta E^{*}$ that were same as samples supplemented with antioxidants (Supplemental Fig. 1).

The color change of HSO samples could be related to the conversion of chlorophyll $a$ to brownish pheophytins, which are known to occur when exposed to heat ${ }^{20}$. Heat treating of $\mathrm{HSO}$ at $70^{\circ} \mathrm{C}$ and $85^{\circ} \mathrm{C}$ produced a significant $(p<0.05)$ loss in total carotenoid content during storage (Fig. 1). While, chlorophyll $a$ is responsible for blue-green color of vegetables, chlorophyll $b$ gives a yellow-green shade in oils. Analysis of Chlorophyll $a$ and $b$ in this study confirmed that chlorophyll $a$ degraded more rapidly than chlorophyll $b$ as the temperature increased (Fig. 1). Losses of carotenoids in these samples suggest that reactions with the carotenoid polyene chain and primary lipid oxidation products occurred to produce radicals yielding carotenoids-adducts ${ }^{21}$. Similar results have been obtained ${ }^{22,23}$ with beta-carotene during heating of red palm olein and olive oil, respectively; over a range (e.g. $50-100^{\circ} \mathrm{C}$ ). The results for carotenoids reduction obtained in the current study is also in agreement with Kadian et al. ${ }^{21}$, who reported a $61-64 \%$ decrease in $\beta$-carotene carrot extract when heated at $70^{\circ} \mathrm{C}$ and $80^{\circ} \mathrm{C}$, respectively.

Effect of heat treatment on HSO peroxidation reactions. In general, HSO is considered to be an unstable oil due to the high proportion of $\alpha$-linoleic acid and $\gamma$-linolenic acid, both of which are susceptible to oxidization during heating and storage ${ }^{24}$. The results of $\mathrm{CDH}$ and $p-\mathrm{AV}$, depicting the peroxidation state of HSO samples both with and without antioxidants including BHT (positive control), $\alpha$ - tocopherol $(\alpha-\mathrm{T})$ and ascorbyl palmitate (AP) in samples incubated for $24 \mathrm{~h}$ at temperatures ranging from 40 to $85^{\circ} \mathrm{C}$ are shown in Fig. 2. This figure also includes the $\mathrm{CDH}$ and p-AV values of $\mathrm{HSO}$ samples that were stored at room temperature $\left(25^{\circ} \mathrm{C}\right)$ for 2 weeks; for a comparison of the accelerated shelf-life study performed under ambient temperature conditions. Conjugated dienes $(\mathrm{CDH})$ measurement tracks thermal oxidation reactions during the early (primary) stages of oxidation; while Anisidine value ( $p-\mathrm{AV}$ ) is useful for evaluating the secondary products of lipid oxidation. As linoleic acid is the predominant fatty acid of $\mathrm{HSO}, p$-AV gives an indication of aldehyde production rate in $\mathrm{HSO}^{25}$. $\mathrm{CDH}$ and $p$-AV values in control HSO samples were 2.75 and 1.45 , respectively, but these values increased significantly $(p<0.05)$ after $24 \mathrm{~h}$ heat treatment. The increasing rate for $p$-AV reached to a plateau after $12 \mathrm{~h}$ heating at $85^{\circ} \mathrm{C}$. No increase or plateau in $p$-AV was reached when samples were stored at room temperature for 2 weeks. A 

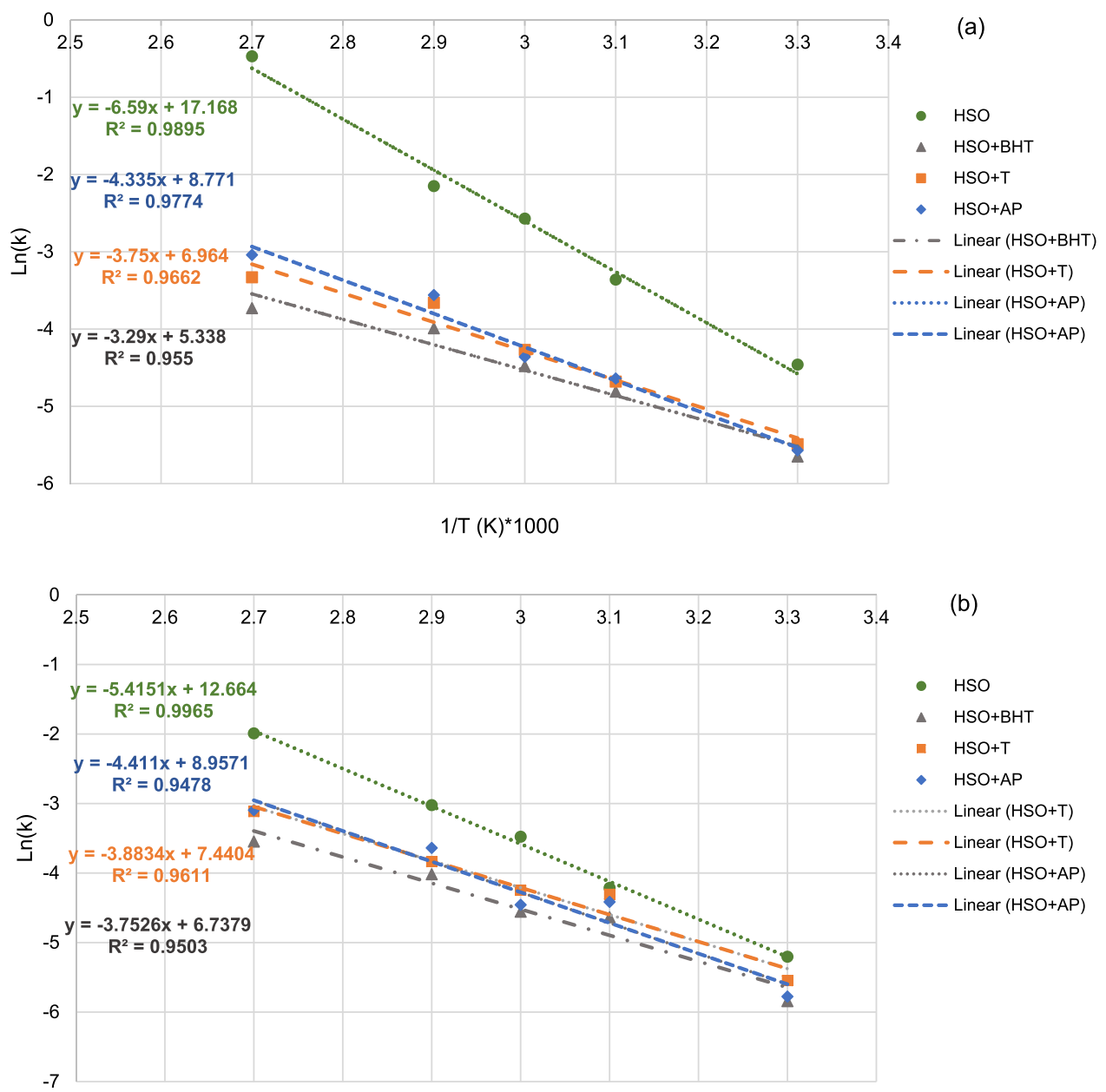

$1 / T(K)^{*} 1000$

Figure 3. Arrhenius plots for calculation of Ea and the extrapolation of $(\mathrm{k})$ at temperatures of 25, 40, 55, 70, and $85^{\circ} \mathrm{C}$ : omega- 6 fatty acids (a) and omega- 3 fatty acids $(\mathbf{b})$.

significant increase $(p<0.05)$ in $p$-AV value of control sample was observed when heated beyond $8 \mathrm{~h}, 4 \mathrm{~h}$ and $2 \mathrm{~h}$ at $55^{\circ} \mathrm{C}, 70$ and $85^{\circ} \mathrm{C}$, respectively.

Adding antioxidants to HSO produced a reduction in $p$-AV by $39-53 \%$ in samples incubated at temperature ranges from $55-85^{\circ} \mathrm{C}$. The relative inhibitory effect of antioxidants on $p$-AV were in the order of $\mathrm{BHT}>\alpha-\mathrm{T}>\mathrm{AP}$ at $70^{\circ} \mathrm{C}$ and $85^{\circ} \mathrm{C}$, respectively and $\mathrm{BHT}>\mathrm{AP}>\alpha-\mathrm{T}$ at $55^{\circ} \mathrm{C}$. Bag and Chattopadhyay ${ }^{26}$ also observed that the inhibition in lipid peroxidation attributed to BHT was $23.2 \%$ higher than $\alpha$-T when added in similar amount $(200 \mu \mathrm{g} / \mathrm{ml})$. We obtained a relatively better inhibitory effect of $\alpha-\mathrm{T}$, compared to $p$-AV at elevated heating temperatures, which translates to a potential for prolonged storage. The results of $\mathrm{CDH}$ and $\mathrm{p}$-AV for the samples stored at $25^{\circ} \mathrm{C}$ also revealed that after 15 days $(360 \mathrm{~h})$, oxidation occurred in $\mathrm{HSO}$ as evidenced by the p-AV value exceeding a score of 20. Adding antioxidants stabilized HSO samples to acceptable levels (reduced p-AV from 27 to 15-17) (Fig. 2), producing the following relative order of inhibition: AP $>$ BHT $>\alpha$-T. Our finding is similar to other researchers, wherein the addition of AP at $400 \mathrm{ppm}$ in both cotton seed and virgin olive oils, respectively during storage at $60^{\circ} \mathrm{C}$ for 28 days resulted in significant reduction of $\mathrm{PV}^{27}$. At elevated temperatures, the addition of antioxidants maintained p-AV values within 20 for $55^{\circ} \mathrm{C}$ and $70^{\circ} \mathrm{C}$, and to within 30 for $85^{\circ} \mathrm{C}$. In general, $\alpha-\mathrm{T}$ was relatively more effective at stabilizing HSO compared to ascorbyl palmitate, albeit both were comparable to BHT. $\alpha-T$ was also found to be an efficient antioxidant when used at concentrations that ranged from 50-200 ppm for delaying the oxidization of sunflower triacylglycerols at $55^{\circ} \mathrm{C}^{28} . \alpha$-T is also relatively more effective than ascorbyl palmitate in delaying oxidation in salad dressing enriched with fish oil during 6 weeks storage at room temperature $^{29}$. It is important to note that BHT, which was the positive control used in this study, consistently provided a better inhibition of $p-\mathrm{AV}$ values as compared to $\alpha-\mathrm{T}$. The mechanisms underlying BHT and $\alpha$-T activity to retard lipid oxidation is by hydrogen donation to lipid peroxyl radicals, which leads to interference in the chain propagation, or initiation stage of lipid oxidation. Antioxidant capacity of AP occurs as a result of scavenging oxygen and thus changing the redox property to a reduced state, that regenerates primary antioxidants, such as tocopherol isomers ${ }^{27},{ }^{30}$. 

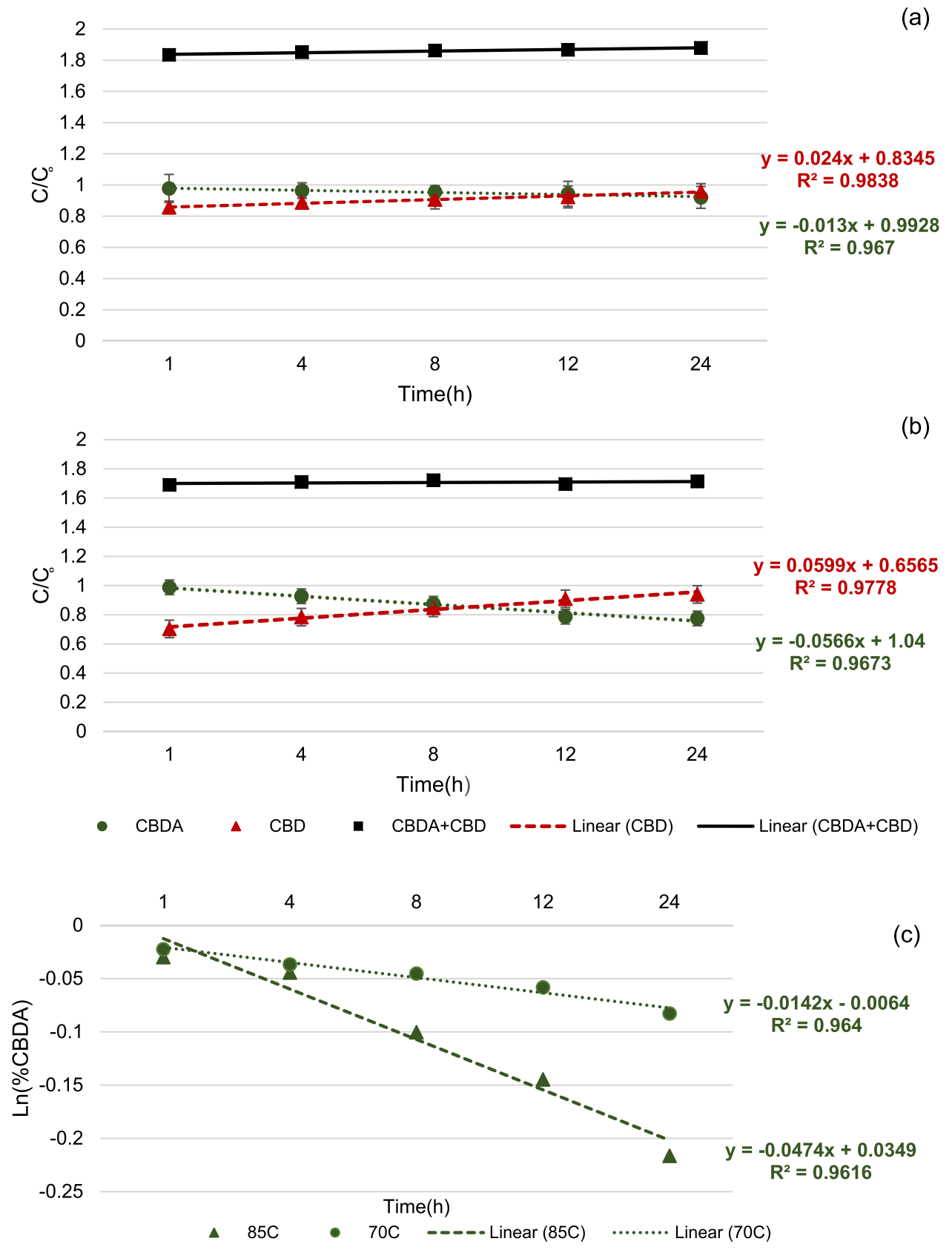

Figure 4. Decarboxylation of CBDA: $70^{\circ} \mathrm{C}(\mathbf{a})$ and $85^{\circ} \mathrm{C}(\mathbf{b})$; Kinetics for decarboxylation of CBDA at 70 and $85^{\circ} \mathrm{C}(\mathrm{C})$.

\begin{tabular}{|l|l|l|l|}
\hline Sample & $\mathbf{K}\left(\mathbf{h}^{-1}\right)$ & $\mathbf{D T 5 0}(\mathbf{h})$ & $\mathbf{D T 9 0}(\mathbf{h})$ \\
\hline HSO (control) & $0.00777 \pm 0.0053^{\mathrm{a}}$ & $88.80 \pm 1.67^{\mathrm{a}}$ & $298.58 \pm 3.76^{\mathrm{a}}$ \\
\hline HSO + BHT & $0.00457 \pm 0.0044^{\mathrm{b}}$ & $150.98 \pm 1.98^{\mathrm{b}}$ & $507.65 \pm 7.85^{\mathrm{b}}$ \\
\hline HSO $+\mathrm{T}$ & $0.00169 \pm 0.0011^{\mathrm{d}}$ & $408.28 \pm 5.98^{\mathrm{d}}$ & $1372.78 \pm 11.34^{\mathrm{d}}$ \\
\hline HSO + AP & $0.00253 \pm 0.0012^{\mathrm{c}}$ & $272.72 \pm 3.13^{\mathrm{c}}$ & $916.99 \pm 9.76^{\mathrm{c}}$ \\
\hline
\end{tabular}

Table 4. Decarboxylation rate constant (k), half-life (DT50), time for 90\% loss (DT90) of CBDA present in HSO samples incubated at $85^{\circ} \mathrm{C}$ for $24 \mathrm{~h}$. Values are the mean es on the same column do not share the same lowercase letters are significantly different at $p<0.05$.

Fatty acids evaluation of HSO. GC-FID/GC-MS analysis. The fatty acid profiles and content in HSO determined by GC-FID and GC-MS analysis are presented in Table 1. In this study, the most abundant fatty acid in $\mathrm{HSO}$ was linoleic acid $(60.52 \pm 0.63 \%)$ followed by $\alpha$-linolenic $(18.44 \pm 0.12 \%)$, oleic $(6.63 \pm 0.11 \%)$ and 
palmitic acid $(6.06 \pm 0.09 \%)$. Previous studies ${ }^{11},{ }^{18},{ }^{31},{ }^{32}$ reported higher amounts of oleic acid (9.56-11.98\%) and lower concentration of linoleic acid (55.05-59.77\%). In our study, we also detected a small but significant amount of stearidonic acid $(0.93 \pm 0.01 \%)$, which compared to the amount reported by Cardillo ${ }^{33}$ in HSO and hulled hemp seed samples. In this study, the degree of unsaturation $(91.12 \%)$ and the ratio of $\omega-6 / \omega-3$ fatty acids $(3.3 / 1)$ remained in agreement with the values reported by other researchers ${ }^{11},{ }^{32}$.

${ }^{1} H$-NMR analysis. We also used NMR to confirm both the PUFA and saturated fatty acid content of HSO. The fatty acid compositions and the ratios among them were determined from the areas from the characteristic signals of each fatty acyl chain (See Supplemental Fig. 2). We confirmed former findings ${ }^{18}$, that at the main composition of fatty acids in HSO include linolenic acid ( $\omega-3)$, linoleic acid ( $\omega-6)$, oleic acid $(\omega-9)$ and saturated fatty acid. The ratio between linoleic acid ( $\omega-6)$ : linolenic acid $(\omega-3)$ and linolenic acid $(\omega-3)$ : oleic acid $(\omega-9)$ was measured to be 3.12 and 2.16, respectively. These data are consistent with the findings obtained using the GC method indicating that NMR analysis enabled ratio configuration of different fatty acids.

Cannabinoid profile of HSO. LC-MS/HPLC-UV and GC/GC-MS have been typically used for identification and quantification of cannabinoids in hempseed oil ${ }^{34-36}$. Using LC-MS and comparing with a mixture of cannabinoids standards in this study, seven cannabinoid compounds including Cannabidivarin (CBDV), CBDA, CBD, Cannabigerol (CBG), and small amounts of Tetrahydrocannabivarin (THCV), THCA and THC $(<0.2 \%)$ were detected (Table 2). Pellegrini et al. ${ }^{36}$ reported that HSO's THC concentration $(25.0 \pm 0.5 \mathrm{ng} / \mathrm{ml})$ was considerably higher than CBD $(3.7 \pm 4.2 \mathrm{ng} / \mathrm{ml})$ and CBN $(2.4 \pm 0.3 \mathrm{ng} / \mathrm{ml})$, respectively. Citti et al..$^{34}$ found more CBDA, CBD and CBN than THCA and THC. In contrast to these other works ${ }^{34,36}, \mathrm{CBN}$ was not detected in our HSO sample.

Kinetic studies. Degradation of omega- 6 and omega- 3 fatty acids. The results for degradation rate constant (k), DT50 and DT90 of total omega- 6 and total omega- 3 fatty acids present in HSO incubated at $25-85^{\circ} \mathrm{C}$ for 24 $\mathrm{h}$ are shown in Table 3 . The Arrhenius plots based on natural logarithm of the degradation constant rate ( $\operatorname{Ln} k$ ) of omega- 6 and omega- 3 fatty acids in HSO, versus the inverse of the temperature $\left(1 / \mathrm{T}^{\circ} \mathrm{K}\right)$ displayed a first order linear relationship ( $R^{2}$ value of 0.9478 to 0.9895$)$ (Fig. 3). A rise of $90.07-95.81 \%$ in the rate constant $(k)$ occurred on increasing the temperature from 25 to $85^{\circ} \mathrm{C}$ in $\mathrm{HSO}$, without addition of antioxidant, showing that degradation of omega- 6 and omega- 3 fatty acids were dependent on temperature. However, adding different antioxidants led to a drop in rate constant $(k)$ to $78.93 \%$. At $25^{\circ} \mathrm{C}$, the predicted half-life (DT50) and DT90 of HSO, without antioxidant were $74.21 \mathrm{~h}$ and $256.51 \mathrm{~h}$ for omega- 6 fatty acids and 125.45 and $418.18 \mathrm{~h}$ for omega- 3 fatty acids, respectively; thus indicating higher stability of omega-3 fatty acids at this temperature. Increasing the temperature to $85^{\circ} \mathrm{C}$ resulted in a greater resistance to omega- 6 fatty acids degradation compared to that of omega-3 fatty acids; according to higher DT50 and DT90 values. At this temperature, the samples with antioxidants added showed improved DT50 and DT90 for both omega-3 and omega- 6 fatty acids. In this regard, BHT acted more efficiently followed by $\alpha-T$ and AP.

Activation energy represents the sensitivity of the compound to degrade due to thermal treatment. In this study, higher $E_{a}$ indicated more susceptibility of the omega- 6 and omega- 3 fatty acids to the thermic changes. All tested HSO samples were less stable at higher temperature $\left(70\right.$ and $\left.85^{\circ} \mathrm{C}\right)$ compared to the lower temperatures $\left(25,40\right.$ and $\left.55^{\circ} \mathrm{C}\right)$. Original heat-treated $\mathrm{HSO}$ had an $E_{a}$ value of 54.78 and $44.97(\mathrm{~kJ} / \mathrm{mol})$ for omega- 6 and omega-3 fatty acids, respectively, signifying the lower resistance to heat from omega-3 fatty acids (Table 3 ). These values are 1.22-2.02 times more than when HSO had antioxidants added, thus showing the effect of antioxidants to reduce thermal oxidation reactions in HSO. This finding was lower than $E_{a}$ for oxidation of HSO previously found at 70,80 and $90^{\circ} \mathrm{C}(69.97 \mathrm{~kJ} / \mathrm{mol})$ by other researchers ${ }^{11}$. They ${ }^{11}$ also reported an exponential relationship between the rate of lipid oxidation and temperature. In our current study, adding antioxidants was more effective in decreasing the activation energy of omega- 6 fatty acids than omega- 3 s. Incidentally, AP was less effective compared to BHT and $\alpha-\mathrm{T}$. This can be related to the heat liability of ascorbic acid and its esteric compounds with a first-order thermal degradation kinetics ${ }^{37}$.

Decarboxylation of cannabidiolic acid (CBDA). In order to study the influence of heat treatment (e.g. 70 and $80^{\circ} \mathrm{C}$ for $24 \mathrm{~h}$ ) on the stability of acidic cannabinoids in HSO, the decarboxylation of acidic cannabinoids was studied. To avoid the evaporation of cannabinoids, decarboxylation studies were conducted in a closed vessel. Due to trace amount of THCA in our HSO sample, CBDA, the most abundant of acidic cannabionod identified in HSO was selected as the chemical marker for decarboxylation studies. The linear regressions of the decarboxylation kinetics of CBDA at temperatures of 70 and $85^{\circ} \mathrm{C}$ in closed condition as well as the samples with antioxidants incubated at $85^{\circ} \mathrm{C}$ for $24 \mathrm{~h}$ are presented in Fig. 4 . The decrease of CBDA during 24 hours incubation of HSO samples at 70 and $85^{\circ} \mathrm{C}$, occurred as a result of decarboxylation reaction and consequent increasing in CBD presumed a first order reaction (Fig. 4). At these temperatures, the sum of loss of CBDA and formation of CBD remained constant (the recorded loss of CBDA at 70 and $85^{\circ} \mathrm{C}$ was $<0.02 \%$ ). Hence, it was assumed that at these temperature, the decarboxylation of CBDA led only to the production of CBD. From the equations, the kinetic parameters have been calculated and recorded for CBDA loss (Table 4). Comparing our results with those of Citti et al. ${ }^{34}$ using CBDA retention in both open and closed condition at temperatures from 80 to $120^{\circ} \mathrm{C}$, the rate constant $(k)\left(3.37 \pm 0.20 \times 10^{-5}\right.$ and $1.01 \pm 0.04 \times 10^{-4}$ at 80 and $90^{\circ} \mathrm{C}$, respectively) was lower than our results. In our study, HSO samples with antioxidants exhibited lower decarboxylation rate of CBDA (Table 4). The presence of hydroxyl groups belonging to antioxidants might decrease the lipid-solubility of CBDA with carboxyl group, leading to protect it from degradation. To have a better understanding of these mechanism, further detailed studies is needed to be performed. 


\section{Conclusion}

Evaluation of oxidative predisposition of HSO exposed to heat treatments with and without the presence of antioxidants ( $\alpha$-Tocopherol, BHT and ascorbyl palmitate) was performed by measuring changes in conjugated diene hydroperoxides $(\mathrm{CDH})$ and $\mathrm{p}$-Anisidine value (p-AV). These chemical markers confirmed the potential of antioxidants to improve the of storage life of HSO. Color changes during heat treatment corresponded to aldehyde formation during lipid peroxidation and/or chlorophyll a degradation. GC-FID/GC-MS followed by ${ }^{1} \mathrm{H}-\mathrm{NMR}$ analysis of HSO confirmed the $\omega-6 / \omega-3$ ratio of 3.12 and 3.3 which is suited for human nutrition. Measuring the kinetic parameter (rate constant $k$ ) for degradation of $\omega-6$ and $\omega-3$ fatty acids, provided the prediction of half-life (DT50) and $90 \%$ loss(DT90) of these fatty acids during storage of HSO at $25^{\circ} \mathrm{C}$. Using HPLC-UV and HPLC/MS analysis, cannabidiolic acid (CBDA) was found to be the major cannabinoid compound in HSO. The decarboxylation kinetics of CBDA to CBD provided an estimation for cannabinoid stability. Further studies are needed to have better understanding of correlations between decarboxylation of acidic cannabinoids and stability of PUFAs in the presence of other antioxidants of mixtures thereof, in stabilized HSO.

Received: 1 September 2019; Accepted: 5 June 2020;

Published online: 29 June 2020

\section{References}

1. Jarzębski, M. et al. Pea Protein for Hempseed Oil Nanoemulsion Stabilization. Molecules 24(23), 4288 (2019).

2. Si-mopoulos, A. P., Leaf, A. \& Salem, N. Jr. Workshop statement on the essentiality of and recommended dietary intakes for Omega-6 and Omega-3 fatty acids. Prostaglandins Leukot Essent Fatty Acids. 63(3), 119-21 (2000).

3. Lemke, S. L. et al. Dietary intake of stearidonic acid-enriched soybean oil increases the omega-3 index: randomized, double-blind clinical study of efficacy and safety. American Journal of Clinical Nutrition 92, 766-75 (2010).

4. Fathordoobady, F., Singh, A., Kitts, D. D. \& Pratap Singh, A. Hemp (Cannabis sativa L.) Extract: Anti-Microbial Properties, Methods of Extraction, and Potential Oral Delivery. Food Reviews International 35(7), 664-684 (2019).

5. Girgih, A. T., Udenigwe, C. C. \& Aluko, R. E. In Vitro Antioxidant Properties of Hemp Seed (Cannabis sativa L.) Protein Hydrolysate Fractions. Journal of the American Oil Chemists' Society (JAOCS) 88(3), 381-389 (2011).

6. Cherney, A. H. \& Small, E. Industrial Hemp in North America: Production, Politics and Potential. Agronomy 6(4), 58 (2016).

7. Crescente, G. et al. Chemical composition and nutraceutical properties of hempseed: an ancient food with actual functional value. Phytochemistry Reviews 17(4), 733-749 (2018).

8. Leizer, C., Ribnicky, D., Poulev, A., Dushenkov, S. \& Raskin, I. The Composition of Hemp Seed Oil and Its Potential as an Important Source of Nutrition. Journal of Nutraceuticals, Functional \& Medical Foods 2(4), 35-53 (2000).

9. Liang, J., Aachary, A. A. \& Thiyam-Holländer, U. Hemp seed oil: Minor components and oil quality. Lipid Technology 27(10), 231-233 (2015).

10. Abuzaytounaand, R. \& Shahidi, F. Oxidative Stability of Flax and Hemp Oils. Journal of the American Oil Chemists' Society, 83 (10) (2006).

11. Gao, F. \& Birch, J. Oxidative stability, thermal decomposition, and oxidation onset prediction of carrot, flax, hemp, and canola seed oils in relation to oil composition and positional distribution of fatty acids. European Journal of Lipid Science and Technology 118, $1042-105$ (2016).

12. Kochhar, S. P. \& Henry, C. J. K. Oxidative stability and shelf-life evaluation of selected culinary oils. International Journal of Food Sciences and Nutrition 60(S7), 289-296 (2009).

13. Anwar, F., Siddiq, S., Iqbal, M. \& Rafique Asi, M. Stabilization of sunflower oil with Moringa oleifera leaves under ambient storage. Journal of Food Lipids 14, 35-49 (2007).

14. Kamkar, A. et al. Antioxidative effect of Iranian Pulicaria gnaphalodes L. extracts in soybean oil. South African Journal of Botany 85 , 39-43 (2013).

15. Kitts, D. D., Singh, A., Fathordoobady, F., Doi, B. \& Pratap Singh, A. Plant Extracts Inhibit the Formation of Hydroperoxides and Help Maintain Vitamin E Levels and Omega-3 Fatty Acids During High Temperature Processing and Storage of Hempseed and Soybean Oils. Journal of Food Science 84(11), 3147-3155 (2019).

16. Aladić, K. et al. \& Šubarićb, D. Cold Pressing and Supercritical CO2 Extraction of Hemp (Cannabis sativa) Seed Oil. Chemical and Biochemical Engineering Quarterly 28(4), 481-490 (2014).

17. Montserrat-de la Paz, S., Marín-Aguilar, F., García-Giménez, M. D. \& Fernández-Arche, M. A. Hemp (Cannabis sativa L.) Seed Oil: Analytical and Phytochemical Characterization of the Unsaponifiable Fraction. Journal of Agricultural Food Chemistry 62, 1105-1110 (2014).

18. Siudem, P., Wawer, I. \& Paradowska, K. Rapid evaluation of edible hemp oil quality using NMR and FT-IR spectroscopy. Journal of Molecular Structure 1177, 204-208 (2019).

19. Obon, J. M., Castellar, R., Alacid, M. \& Fernandez-Lopez, J. A. Production of a red-purple food colorant from Opuntia stricta fruits by spray drying and its application in food model systems. Journal of Food Engineering 90(4), 471-479 (2009).

20. Cervantes-Paz, B. et al. Effect of Heat Processing on the Profile of Pigments and Antioxidant Capacity of Green and Red Jalapeño Peppers. Journal of Agricultural and Food Chemistry 60, 10822-10833 (2012).

21. Kadian, S. S., Sharma, A. \& Sood, D. R. Effect of light and heat on stability of crude carotenoid extract from natural sources. International Journal of Pharmaceutical Sciences and Research 4(6), 2415-2418 (2013).

22. Ahmed A. S., Abdulah A. \& Aini I. N. Changes of $\beta$-carotene content during heating of red palm olein. Journal of Oil Palm Research, Special Issue-April 2006, 99-102 (2006a).

23. Zeb, A., Khan, S., Khan, I. \& Imbran, M. Effect of temperature, UV, sun and white lights on the stability of olive oil. Journal of the Chemical Society of Pakistan 30, 790-794 (2008).

24. Zhong, Y. \& Shahidi, F. Lipid oxidation and improving the oxidative stability. Chemical Society Reviews 39, 4067-4079 (2010).

25. Laguerre, M., Lecomte, J. \& Villeneuve, P. Evaluation of the ability of antioxidants to counteract lipid oxidation: Existing methods, new trends and challenges. Progress in Lipid Research 46(5), 244-282 (2007).

26. Bag, A. \& Chattopadhyay, R. R. Evaluation of antioxidant potential of essential oils of some commonly used Indian spices in in vitro models and in food supplements enriched with omega- 6 and omega-3 fatty acids. Environmental Science and Pollution Research 25(1), 388-398 (2018).

27. Javidipour, I., Tüfenk, R. \& Baştürk, A. Effect of ascorbyl palmitate on oxidative stability of chemically interesterified cottonseed and olive oils. Journal of Food Science and Technology 52(2), 876-884 (2015).

28. Lee, J. M., Chung, H., Chang, P. S. \& Lee, J. H. Development of a method predicting the oxidative stability of edible oils using 2,2-diphenyl-1-picrylhydrazyl (DPPH). Food Chemistry 103(2), 662-669 (2007).

29. Let, M. B., Jacobsen, C. B. \& Meyer, A. S. Ascorbyl palmitate, gamma-Tocopherol, and EDTA affect lipid oxidation in fish oil enriched salad dressing differently. Journal of agricultural and food chemistry, 21, 55(6), 2369-75 (2007). 
30. Elisia, I. \& Kitts, D. D. Different tocopherol isoforms vary in capacity to scavenge free radicals, prevent inflammatory response and induce apoptosis in both adult- and fetal-derived intestinal epithelial cells. Biofactors 39, 663-667 (2013).

31. Da Porto, C., Decorti, D. \& Tubaro, F. Fatty acid composition and oxidation stability of hemp (Cannabis sativa L.) seed oil extracted by supercritical carbon dioxide. Industrial Crops and Products 36(1), 401-404 (2012).

32. Teh, S. S. \& Birch, J. Physicochemical and quality characteristics of cold-pressed hemp, flax and canola seed oils Journal of Food Composition and Analysis, 30 (1), 26-3 (2013).

33. Cardillo, A. The effects of hempseed oil and hulled hempseed on health biomarkers. Master of Science Thesis. Department of Human Nutritional Sciences. University of Manitoba, http://hdl.handle.net/1993/33424 (2018).

34. Citti, C., Pacchetti, B., Vandelli, M. A., Forni, F. \& Cannazza, G. Analysis of cannabinoids in commercial hemp seed oil and decarboxylation kinetics studies of cannabidiolic acid (CBDA). Journal of Pharmaceutical and Biomedical Analysis 149(5), 532-540 (2018).

35. Happyana, N., Agnolet, S., Muntendam, R., Dam, A. V., Schneider, B. \& Kayser, O. Analysis of cannabinoids in laser-microdissected trichomes of medicinal Cannabis sativa using LCMS and cryogenic NMR. Phytochemistry 87, 51-59 (2013).

36. Pellegrini, M., Marchei, E., Pacifici, R. \& Pichini, S. A rapid and simple procedure for the determination of cannabinoids in hemp food products by gas chromatography-mass spectrometry. Journal of Pharmaceutical and Biomedical Analysis 36(5), 939-946 (2005).

37. Marfil, P. H. M., Santos, E. M. \& Telis, V. R. N. Ascorbic acid degradation kinetics in tomatoes at different drying conditions. LWT - Food Science and Technology 41(9), 1642-1647 (2008).

\section{Acknowledgements}

The authors would like to acknowledge MITACS Accelerate Grant (Grant number IT0676) for funding this study. Part of the research was also funded by the National Science and Engineering Research Council of Canada (NSERC) Discovery Grant Number RGPIN-2018-04735.

\section{Author contributions}

A.P.S. and D.D.K. conceptualized the study. F.F., Y.G. and A.S. made the experimental plan and conducted the experiments. A.P.S., F.F. and D.D.K. analyzed the data and summarized the results. A.P.S. and F.F. wrote the first draft of the manuscript. All authors edited and reviewed the manuscript.

\section{Competing interests}

The authors declare no competing interests.

\section{Additional information}

Supplementary information is available for this paper at https://doi.org/10.1038/s41598-020-67267-0.

Correspondence and requests for materials should be addressed to A.P.S.

Reprints and permissions information is available at www.nature.com/reprints.

Publisher's note Springer Nature remains neutral with regard to jurisdictional claims in published maps and institutional affiliations.

(c) (i) Open Access This article is licensed under a Creative Commons Attribution 4.0 International License, which permits use, sharing, adaptation, distribution and reproduction in any medium or format, as long as you give appropriate credit to the original author(s) and the source, provide a link to the Creative Commons license, and indicate if changes were made. The images or other third party material in this article are included in the article's Creative Commons license, unless indicated otherwise in a credit line to the material. If material is not included in the article's Creative Commons license and your intended use is not permitted by statutory regulation or exceeds the permitted use, you will need to obtain permission directly from the copyright holder. To view a copy of this license, visit http://creativecommons.org/licenses/by/4.0/.

(C) The Author(s) 2020 